\title{
APPLICATION OF BRAIDED FIBRE REINFORCED COMPOSITE RODS IN CONCRETE REINFORCEMENT
}

\author{
R. Fangueiro ${ }^{1, a}$, G. Sousa ${ }^{1, b}$, F. Soutinho ${ }^{1, c}$, S. Jalali ${ }^{2, d}$ \\ and M. de Araújo ${ }^{1, e}$ \\ ${ }^{1}$ Department of Textile Engineering, University of Minho, Campus de Azurém, \\ 4800 Guimarães, PORTUGAL \\ ${ }^{2}$ Department of Civil Engineering, University of Minho, Campus de Azurém, \\ 4800 Guimarães, PORTUGAL \\ arfang@det.uminho.pt, ${ }^{b}$ gmsousa@clix.pt, ${ }^{\text {cfilipesoutinho@det.uminho.pt, }}$ \\ dsaid@civil.uminho.pt, ${ }^{\mathrm{e}}$ marioaraujo@det.uminho.pt
}

Keywords: braided fabric, composite material, concrete reinforcement, corrosion

\begin{abstract}
This paper describes the work that is being done at the University of Minho concerning the development of braided rods for concrete reinforcement. A preliminary research study has been conducted to understand the mechanical behaviour of braided fabrics. Various samples have been produced varying the type of fiber (glass, polyester and aramid), the type of braided fabric (simple, hybrid and core reinforced) and in the latter case, the number of core reinforcing yarns. The tensile properties of these samples have been evaluated and the results presented. The influence of each factor on the tensile properties of braided fabrics has also been analysed and discussed. In order to produce braided reinforced composite rods to use as a concrete reinforcement, a special technique has been developed using a standard vertical braiding machine. The braided reinforced composite materials have been produced in rib structure to improve adhesion between them and the concrete. Special samples have been prepared and tested to evaluate the adherence between both materials involved. The tensile and bending properties of braided reinforced composite rods have been evaluated and the results obtained presented and discussed.
\end{abstract}

\section{Introduction}

In building construction, concrete structures are subjected to repeated loading and to aggressive agents which may lead to poor mechanical performance of the structures with time. One of the most serious problems affecting concrete is corrosion of the steel armours. As shown in Fig. 1 this corrosion may occur due to its reaction with carbon dioxide or to the action of chlorides. In the first case, the reaction with the carbon dioxide existing in the atmosphere leads to a gradual decrease in concrete alkalinity. When the concrete covering the armours looses its alkalinity, the oxide layer protecting the steel may be destroyed, thus leading to the development of the "stack effect", i. e., the formation of electric currents which are responsible for the corrosion of the steel. The action of chlorides resulting from deteriorated construction materials or from their migration to the interior of the structure, increases significantly the potential for steel corrosion. This fact is particularly hazardous in marine or polluted environments [1]. 


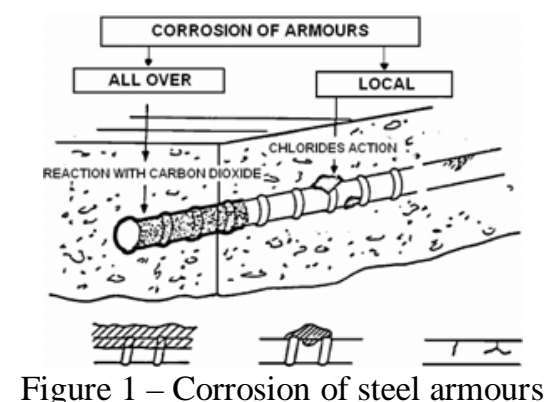

Braiding technique is probably the most ancient production process of textile structures. Normally used for ropes and cables, braided fabrics are also very interesting for composite reinforcements due to their characteristics: in-plane multiaxial orientation, conformability, excellent damage tolerance and cost. Braiding technique can produce a wide range of preforms for composite reinforcements (T's, I, hollow fabrics), the number of yarn bobbins in the braiding machine limits however the piece dimensions.

Replacement of the steel reinforcement in concrete structures with more corrosion resistant substitutes such as composites is rapidly becoming a more economical option for construction facilities worldwide [2, 3, 4, 5, 6]. Composites can be used in new or repaired reinforced concrete structures. In general, composites have high strength, a range of moduli and low ultimate tensile strains compared to steel. The stress-strain behavior of all of these fiber systems is linear up to failure, which makes it impossible to have significant hysteretic behavior. In spite of their superior light weight, corrosion resistance and non-magnetic properties, the lack of material ductility and energy absorbing capabilities is a severe limitation of all these fiber systems if they are to be considered for earthquake resistant applications.

In order to achieve ductility in reinforced concrete structures without using conventional steel rebar, a new design methodology was introduced by Somboonsong et al [7],. to identify suitable composite materials that mimic the stress-strain characteristics of steel. The technology of braiding, as detailed by Ko and Pastore [8], is a well established technology which intertwines three or more strands of yarns to form a tubular structure with various combinations of linear or twisted core materials. By judicious selection of fiber materials and fiber architecture for the braid sleeve and the core structure, the load-deformation behavior of the braided fibrous assembly can be tailored.

\section{Braided Reinforced Composite Rods}

In order to overcome problems encountered during previous testing on concrete reinforced by glass-braided fabrics, braided reinforced composite rods have been produced and tested. Moreover, the adherence between concrete and composite rods has also been evaluated and discussed.

Production. The samples have been produced on a conventional braiding machine specially adapted to impregnate simultaneously the braided fabrics. In order to increase roughness of the braided reinforced composite material rods, and then its adhesion to the concrete, braided fabrics have been produced as a rib structure, as shown in Figure 2. This rib structure is provided by thicker yarns that are used in the braiding machine in a rate of 7 normal to 1 thicker. For a stronger effect on roughness the number of thicker yarns could be increased during braiding process. 


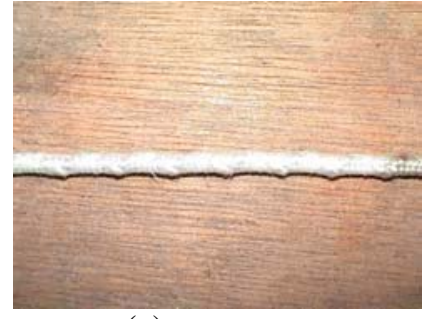

(a)

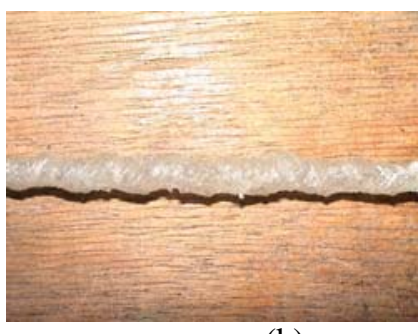

(b)

Figure 2 - Rib structure

(a) braided fabric (b) braided reinforced composite rod

Glass braided fabrics have been produced and simultaneously impregnated with a polyester thermosetting resin during the braiding process. The characteristics of the composite material rods produced are shown in Table 1.

\begin{tabular}{|c|c|c|c|c|}
\hline Braided fabric & Material & $\begin{array}{c}\text { Thickness } \\
\text { (mm) }\end{array}$ & $\begin{array}{c}\text { Fiber volume } \\
\text { fraction (\%) }\end{array}$ & Resin \\
\hline Core reinforced & $\begin{array}{c}\text { Braided yarns: } 110 \text { tex, E glass } \\
\text { fiber } \\
\text { Core reinforcement: 12 E glass } \\
\text { fiber 900 tex rovings }\end{array}$ & 3.7 & 63.44 & polyester \\
\hline
\end{tabular}

Table 1 - Characteristics of the composite material rods

Mechanical Properties. The evaluation of tensile properties of the braided reinforced composite rods previously produced, experimental work has been undertaken using a HOUNSFIELD universal tensile tester, according to the ASTM D638 standard, at a speed of $1 \mathrm{~mm} / \mathrm{min}$. The results obtained are shown in Table 2 while Figure 3 shows the typical loadextension curve.

\begin{tabular}{|c|c|c|}
\hline $\begin{array}{c}\text { Maximum stress } \\
\text { (MPa) }\end{array}$ & $\begin{array}{c}\text { Extension at maximum } \\
\text { stress (\%) }\end{array}$ & $\begin{array}{c}\text { Young's } \\
\text { modulus (MPa) }\end{array}$ \\
\hline 946.81 & 6.93 & 17700 \\
\hline
\end{tabular}

Table 2 - Tensile properties of composite reinforced rods

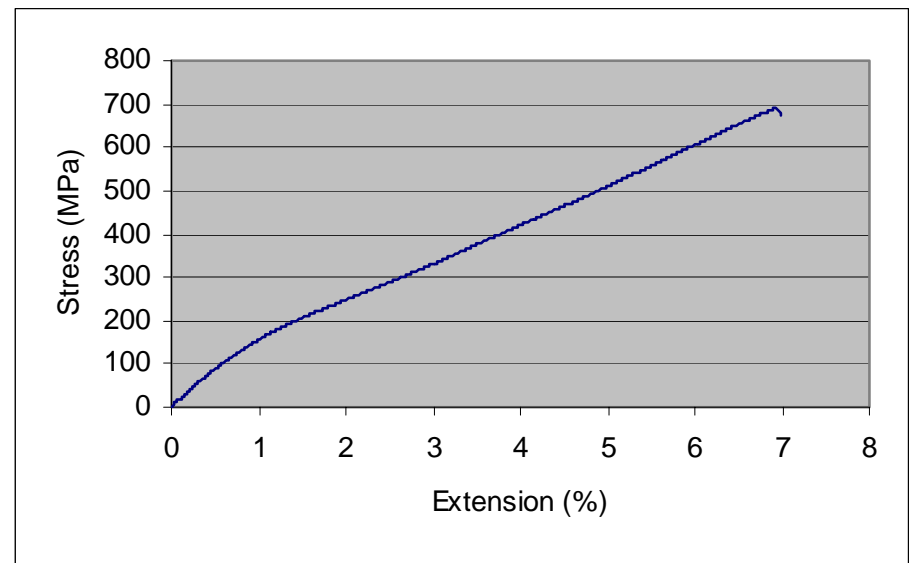

Figure 3 - Typical stress-strain curve for braided reinforced composite rods

Adhesion to the Concrete. In order to evaluate the adherence between braided composite rods and concrete, 8 samples have been prepared. Samples have been tested on an universal tensile tester, at a cross-head speed of $0.1 \mathrm{~mm} / \mathrm{seg}$, according to the standard NP EN 10002-1 
used usually for steel. Braided composite rods have adhered completely to concrete up to its tensile breaking strength.

\section{Concrete Beams Reinforced By Braided Reinforced Rods}

Samples Preparation. Three concrete beams reinforced by an armour of braided composite rods (Figure 4) have been prepared, jointly with three concrete beams reinforced by steel. The dimensions of the beams are presented in Figure 5.

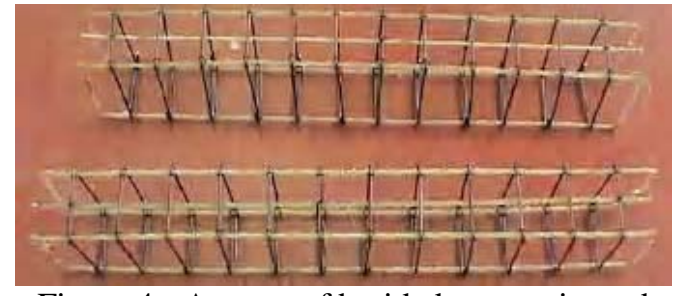

Figure 4 - Armour of braided composite rods

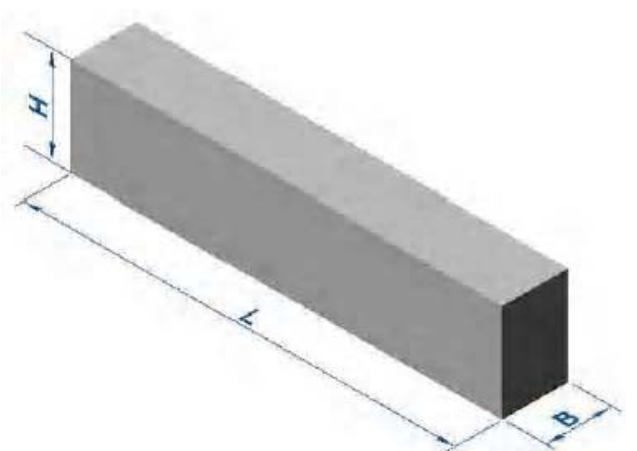

Figure 5 - Beam dimensions $(\mathrm{B}=10 \mathrm{~cm} \mathrm{H}=15 \mathrm{~cm} \mathrm{~L}=65 \mathrm{~cm})$

The curing process occurred in three different steps: $24 \mathrm{~h}$ in the concrete application place; 20 days in water at a temperature of $20^{\circ} \mathrm{C} ; 6$ days at a room temperature of $20^{\circ} \mathrm{C}$.

Testing and Results. The beams have been tested in a servo-controlled system with a speed of $10 \mu \mathrm{m} / \mathrm{s}$. The elongation and the loads correspondents have been registered. (Figure 6)

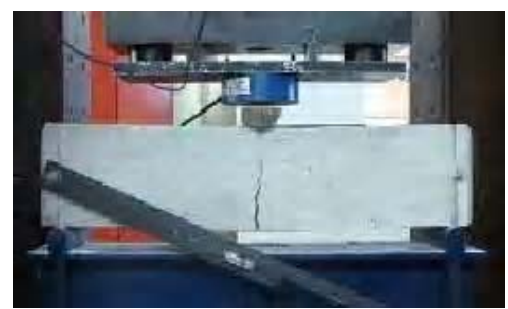

Figure 6 - Bending test of concrete beams reinforced by braided reinforced composite rods

Tables 3 and 4 are presenting the results obtained for each type of beams tested.

\begin{tabular}{|l|c|c|}
\cline { 2 - 3 } \multicolumn{1}{c|}{} & $\begin{array}{c}\text { Load } \\
\text { (KN) }\end{array}$ & $\begin{array}{c}\text { Displacement } \\
\text { (mm) }\end{array}$ \\
\hline Beam 1 & 58.1 & 4.4 \\
\hline Beam 2 & 63.3 & 2.5 \\
\hline Beam 3 & 60.1 & 3.4 \\
\hline Mean & 60.5 & 3.4 \\
\hline
\end{tabular}

Bending test results for beams reinforced by steel rods

\begin{tabular}{|l|c|c|}
\cline { 2 - 3 } \multicolumn{1}{c|}{} & $\begin{array}{c}\text { Load } \\
\text { (KN) }\end{array}$ & $\begin{array}{c}\text { Displacement } \\
\text { (mm) }\end{array}$ \\
\hline Beam 1 & 32.5 & 8.2 \\
\hline Beam 2 & 30.3 & 4.8 \\
\hline Beam 3 & 30.7 & 6.4 \\
\hline Mean & 31.3 & 6.5 \\
\hline
\end{tabular}

Bending test results for beams reinforced by braided reinforced composite rods

Figure 7 presents a beam after testing, where are visible the braided reinforced composite rods broken. 


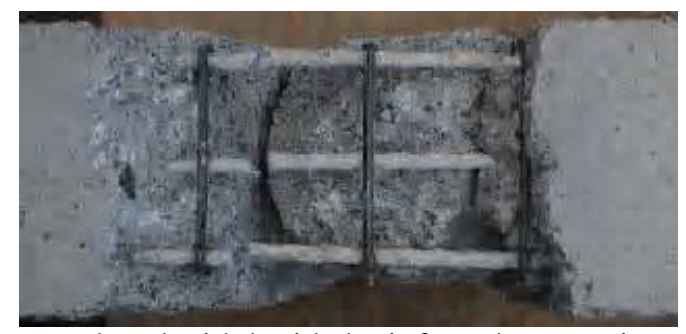

Figure 7 - Beam produced with braided reinforced composite rods after testing

Figure 8 presents the load-extension curves for each type of beam tested.

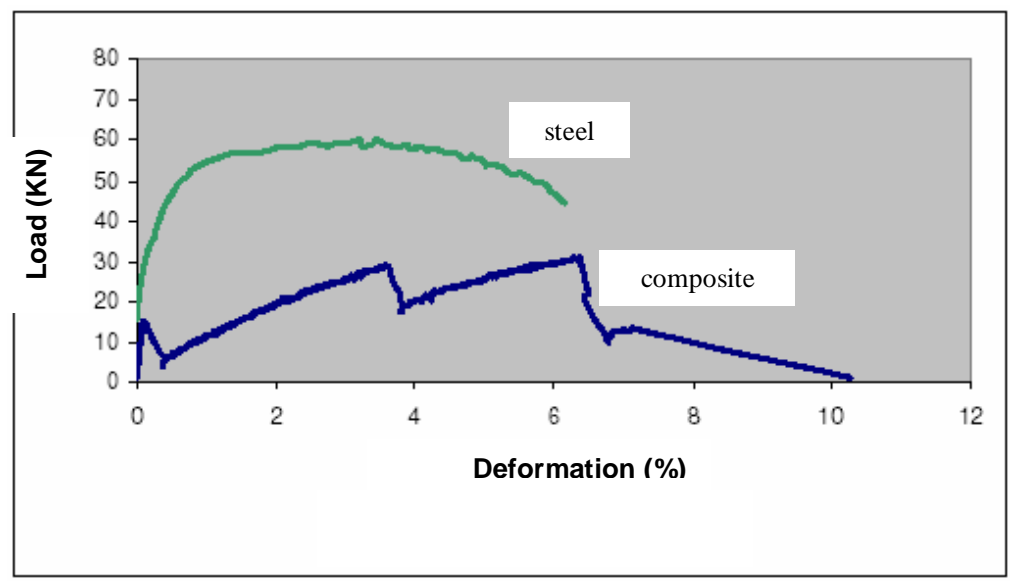

Figure 8 - Load-extension curve for concrete beams reinforced by braided fibre reinforced composite rods

\section{Conclusions}

Analysing the results obtained and the correspondent load-extension curves it is possible to detect different performances between both types of beams tested. The steel reinforced beams are bearing the double of the load supported by the composite reinforced ones. Moreover, the extension values of the steel reinforced beams are lower than those obtained for the composite reinforced ones. In the load-extension curves obtained for the composite reinforced beams, several peaks are visible corresponding to the breakage of each braided composite rod used in the armour. These peaks are showing that the material (concrete+composite) is not working as a whole material. Besides, analysing the first peak, it is possible to conclude that the composite rod is not taking the load immediately after the concrete reinforcement. This behaviour could be explained by the non-uniform tension of the composite rods in the concrete and by their lower modulus when compared with the steel rods used.

Further research work is being undertaken in order to overcome the problems encountered within this work. The technology used to produce the braided composite rods is being improved in order to allow the placement of straight fibers inside the braided fabric and to allow a better distribution of the resin. The samples are being produced with more rovings so that the mechanical properties of the material could be improved. Next beams will be produced longer in order to enable four points bending tests so that more representative results could be obtained.

\section{References}

[1] Sousa, G. (2004), Braided structures for concrete reinforcement, Master Thesis, University of Minho, Guimarães.

[2] Mufti, A., Erki, M. A. and Jaeger, L. (1991). Editors, Advanced composite materials with application to bridges, Canadian Society of Civil Engineers, Montreal. 
[3] Iyer, S. L. and Sen, R. (1991). Editors, "Advanced composite materials in civil engineering structures", Proc. Specialty Conf., Las Vegas, Jan. 31- Feb. 1, American Society of Civil Engineering, New York, NY.

[4] Nanni, A. and Dolan C. W. (1993). Editors, "Fiber-reinforced-plastic reinforcement for concrete structures", Proceedings of International Symposium, Vancouver, ACI SP-138.

[5] Basham, K. D. (1994). Editor, "Infrastructure: new materials and methods of repair", Proc., Third Materials Engineering Conf., San Diego, Nov. 13-16, American Society of Civil Engineering, New York, NY.

[6] Saadatmanesh, H. and Ehsani, M. R. (1996). Editors, "Fiber composites in infrastructure", Proc. First International Conf. on Composites in Infrastructure, Tucson, Arizona, Jan. 15-17, Dept. of Civil Eng. and Eng. Mech., University of Arizona.

[7] Somboonsong, W., Ko, F. K., and Harris, H. G. (1998). "Ductile hybrid fiber reinforced plastic (FRP) rebar for concrete structures: design methodology," ACI Materials Journal, V. 95, No. 6, Nov.-Dec., pp. 655-666.

[8] Pastore, C., Ko, F. (1998), Braided Hybrid Composites”, NTC Research Project F98-P01, USA. 